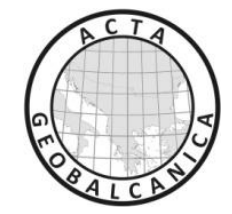

\title{
INDICATIVE HAZARD MAPS FOR LANDSLIDES IN STYRIA; AUSTRIA
}

\author{
Herwig Proske $e^{1}$ \& Christian Bauer ${ }^{1 / 2}$ \\ ${ }^{1}$ Joanneum Research, Graz, Austria \\ ${ }^{2}$ Karl Franzens University Graz, Austria \\ Corresponding author: herwig.proske@joanneum.at
}

\begin{abstract}
This study presents Indicative Hazard Maps for gravitational mass movements for the whole of the Province of Styria (Austria) aiming at implementing these maps into the spatial and forestal planning strategies of the provincial administration. Processes taken into account were deep-seated and shallow landslides as well as stone and rock falls. An extensive landslide inventory was generated, based on recently recorded airborne laserscanning data. The landslide susceptibility modelling was based on a statistical approach (logistic regression). This contribution is focused on the methodological approach in generating Indicative Hazard Maps for landslides at regional scale. Due to process-complexity and scale-dependency of input data, landslide susceptibility modelling is still subject to many uncertainties. These will be further addressed in the present contribution.
\end{abstract}

Keywords: Indicative Hazard Map, Airborne Laserscanning Data, Landslides. Logistic Regression.

\section{INTRODUCTION}

From 2014 to 2015 Indicative Hazard Maps for gravitational mass movements were generated at the Institute for Information and Communication Technologies of JOANNEUM RESEARCH (Graz, Austria) for the whole of the Province of Styria (Austria). The project was funded by the European Agricultural Fund for Rural Development and supported by the Austrian Federal Ministry of Agriculture, Forestry, Environment and Water Management, the Styrian Forestry Board and the Forest Association Styria. Processes taken into consideration were (a) deep-seated landslides, (b) shallow landslides, and (c) stone and rock falls. The contribution is focused on (a) the methodological approach in generating Indicative Hazard Maps for landslides and (b) the generation of an area-wide landslide inventory.

According to the Swiss recommendations for spatial planning and natural hazards [2] an Indicative Natural Hazard Map is defined as an area-wide presentation of the susceptibility of a region with regard to the occurrence of natural hazards. Such maps therefore give an overview of possible hazards, its accuracy level corresponding to a scale of 1:25.000. Indicative Natural Hazard Maps do not provide any information regarding the temporal probability, the magnitude or the possible landslide propagation regions but only defines possible areas of activation. The decisive advantage of an Indicative Hazard Map is the efficient, cost-saving and above all, area-wide 
identification of hazard zones. The extensive application of the same methodical approach ensures excellent comparability of the results in natural as well as in administrative dimensions. Indicative Hazard Maps therefore can be used for decisions in spatial planning prior to land use designations, for forestal planning strategies (e.g. designation of protective forests) and in hazard zoning of the disaster management authorities.

\section{INVESTIGATION AREA}

The Province of Styria, one of nine Austrian provinces, covers approx. $16.400 \mathrm{~km}^{2}$. The area is characterized by a great variety of natural landscapes including high mountain regions in the Northern and Central Alps, several inner alpine basins and distinct longitudinal valleys as well as extensive foothills of the Alps to the southeast with hills and terraces of low topographic energy. This variety is a consequence of the heterogeneous geology with a wide range of rocks. Whereas the Northern Alps are mainly built by different carbonates, the Central Alps are dominated by metamorphic rocks (primarily gneiss and mica schists). Additionally, heavily tectonized paleozoic phyllites and black schists play a significant role.

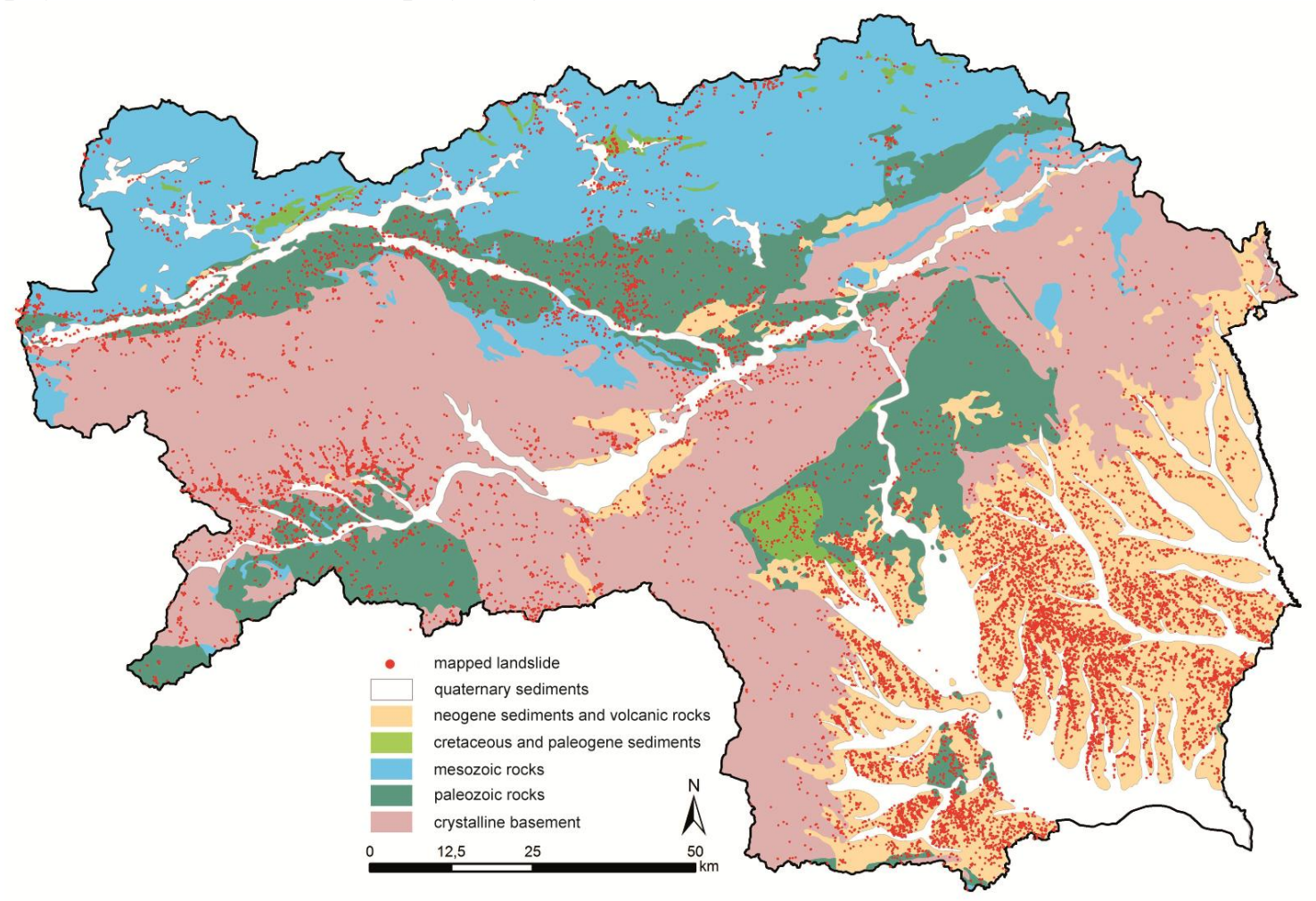

Figure 1: Overview of geological main units and of the mass movement inventory based on ALS-data

In the southeastern foothills of the Alps, the Styrian Basin, alternating sequences of heterogeneous neogenic basin deposits (gravel, sand, clays) are widespread. Due to this broad variety of rocks, showing very different geotechnical characteristics, the basic landslide disposition in the Province of Styria is distributed most unevenly: although landslides occur in any of the geological main units, they are a dominating geomorphological process in the neogenic sediments of the Styrian Basin, the paleozoic 
phyllitic rocks as well as the mica schists which are widespread in the Niedere Tauern (cf. Fig. 1).

\section{DATA BASE}

The most decisive database for the statistical modelling of mass movement susceptibility is an exact and representative inventory. Different types of event inventories exist: (1) historical data from archives; (2) field mapping results; (3) information derived from remote sensing data, and (4) combined inventories [1]. The quality of any modelling result directly depends on the quality of the input data. Three main requirements have to be fulfilled: (1) correctness with regard to the content, (2) accurate geographic positioning, and (3) exact process-related attribution.

Inventories which are based on archive data, in most cases only include those events which caused some kind of damage; even the given position in many cases refers to the damaged object (or even to the owner of the damaged object). Mass movements occurring in remote areas without significant damages normally are not documented. Moreover, information about the source area of the movement - which is most important for the susceptibility modelling - and information about the process type in many cases are not available. A critical review of such type of inventory therefore has to be performed to obtain reliable results of any statistical modelling. In the Province of Styria a Digital Landslide Register is compiled by the Department of Water Management, Resources and Sustainability of the Styrian Regional Government.

Field data in many cases give detailed information about the process type as well as about the date and the trigger of the event (e.g. heavy rainfall). Because of the high effort regarding time and financial resources such data exist only in some selected small scale study areas of Styria (e.g. in South-Eastern Styria) and therefore do not meet the requirements with regard to data representativeness. Anyway, for validation and verification purposes field data represent most useful datasets

Regarding Remote Sensing data, first and foremost the airborne Laserscan data (ALSdata) representing a high resolution basis for localizing deep-seated landslides have to be mentioned. This ALS-survey was completed for the whole of the Province of Styria in 2014. The penetration of laser pulses gives exact terrain information even in areas with high vegetation density. The younger and more active a mass movement, the more distinct the typical features (e.g. tension cracks, scarp, deposition area) can be seen in the field and in the ALS based Digital Terrain Model (DTM). These features are then modified by erosion and anthropogenic activity. Normally it turns out that events on agricultural areas will be made unrecognizable by human activities very quickly [1], [7]. Shallow landslides may be identified by means of orthophotos. In this case it has to be considered that the date when the picture was taken with regard to the triggering event is decisive, as the ground vegetation normally closes within short time (except in highaltitude areas).

The most promising approach for the generation of representative event inventories in forested, unforested as well as in landscapes which are characterized by intense human activity, proved to be a combination of the analysis of archive data with the visual interpretation of Remote Sensing data (ALS-data, orthophotos) followed by random field checks. Such approach was followed in the presented study. By visual interpretation of ALS-data more than 20.000 indications of deep-seated landslides could 
be identified (Fig. 1). These indications incorporate typical geomorphological structures like scarps, destructed linear elements (roads, edges of the slopes) in the zones of transport and rock accumulations in the deposition areas. These data were complemented by available archive data.
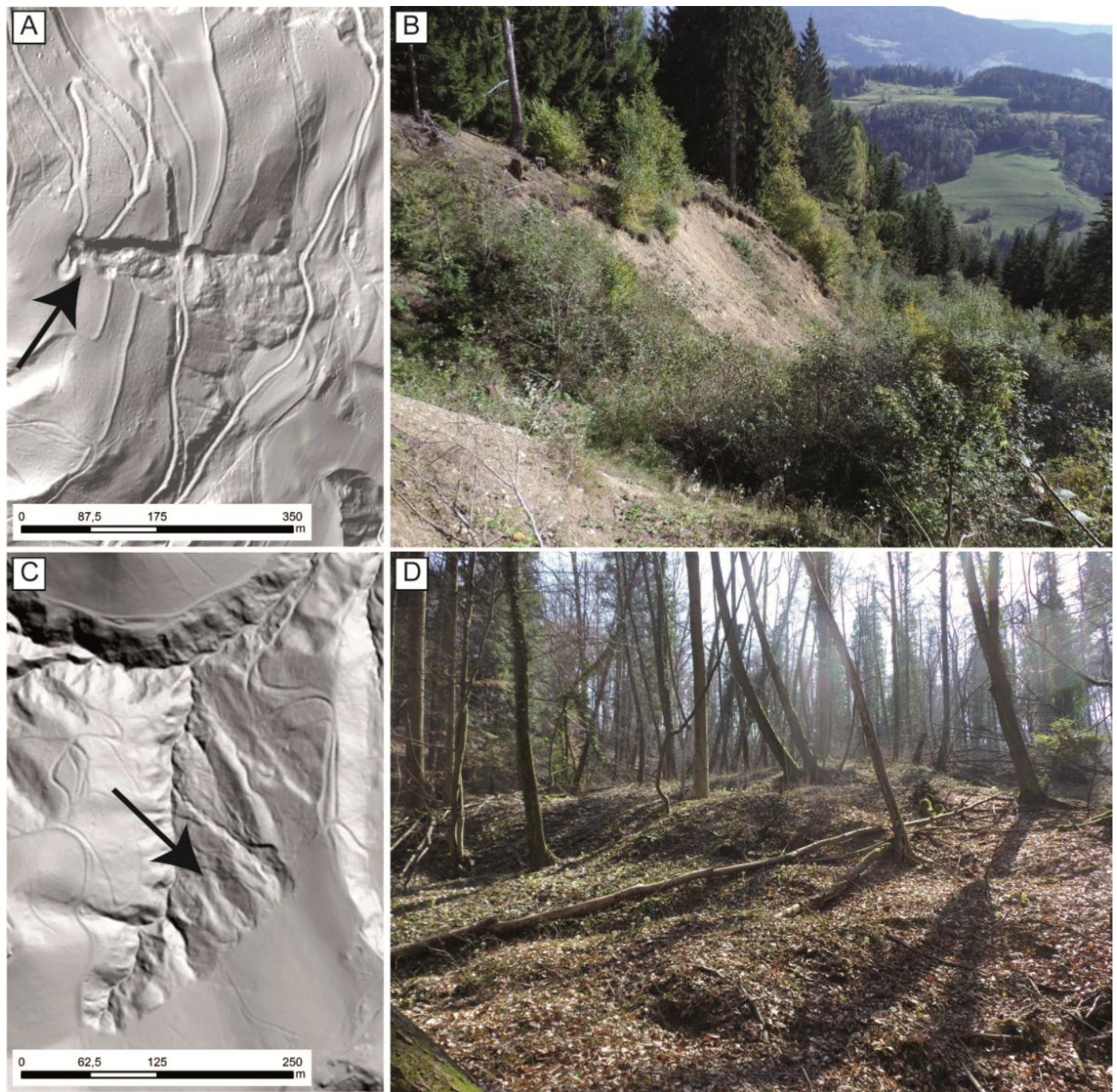

Figure 2: Examples of landslides of class $1(\mathrm{~A}, \mathrm{~B})$ and class 2 (C, D) respectively: DTM hillshade and field situation

Taking into account the presence and characteristics of geomorphological features the identified landslides were assigned to one of two categories:

Class 1: distinct gravitative landslides: obvious scarp and destructed linear elements in the zones of transport and/or obvious rock accumulations (cf. Fig. 2, A, B)

Class 2: probable gravitative landslides: indistinct scarp, no destructed linear elements in the zones of transport, indistinct or missing accumulations (cf. Fig. 2, C, D)

Regarding influencing factors, relevant morphometric parameters (slope, exposition, curvature (total, profile, plan), flow accumulation and size of catchment area, landforms, topographical position index) were calculated based on the 1m grid DTM. 
Furthermore, a digital geological map representing a 1:50.000 reference scale is available in the GIS database of Styria. In fact, the state of mapping is very inconsistent as most diverging base maps with regard to qualitative standards were compiled. Especially the delineation of quaternary loose sediments (e.g. alluvial deposits, terraces) in many cases is incompatible with the high-resolution DTM. Overlays of both datasets show that alluvial deposits are not only displayed in the gentle valley bottoms but sometimes also on very steep slopes (cf. Fig. 3).

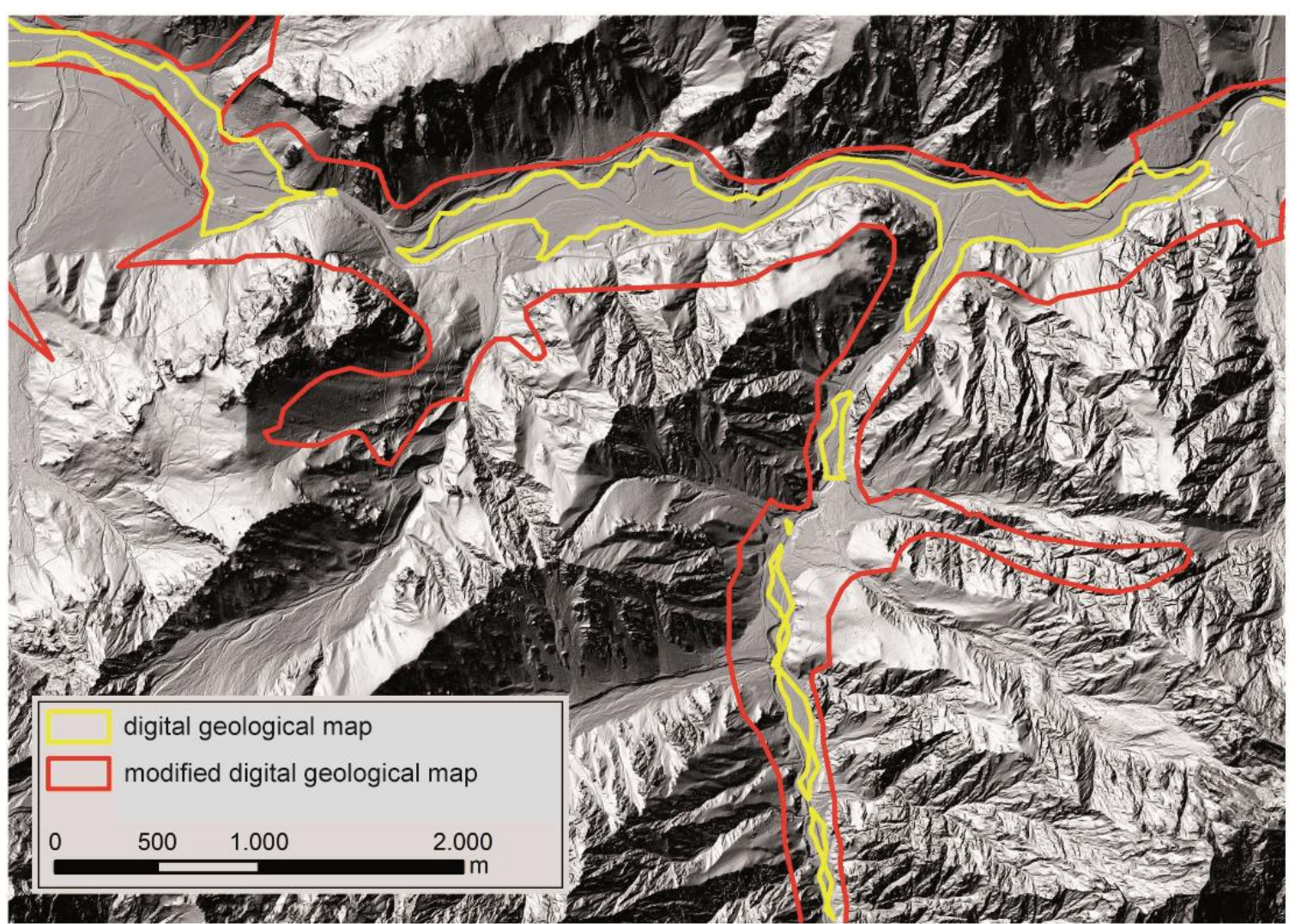

Figure 3: Result of the revision of alluvial sediments by means of an example from Northern Styria

To avoid wrong statistical correlations, these inaccuracies were corrected following an approach which was developed by the Austrian Institute of Technology, Health \& Environment Department within the frame of the MoNOE project [1]. The correction of quaternary sediments resulted in gaps in the bedrock lithology. To get an area-wide grid file these gaps had to be filled by an automatic procedure. Grid cells without lithological information therefore were filled with the values of the units in immediate vicinity in an orographic higher position. Following this step, lithological units were merged into 16 relevant geotechnical-lithological units.

Landuse and landcover data focused on forest parameters which were derived from a Digital Surface Model (based on ALS-data) and satellite data (Rapid Eye Imagery). The estimated parameters are forest type, stem number, height of upper layer, vertical structure, and mean height.

Finally, forest roads were mapped area-wide based on a partly automatic approach using ALS-data and orthophotos. The total length of this kind of infrastructure in the Province of Styria is more than $46.000 \mathrm{~km}$. Especially with regard to the release of shallow landslides, forest roads proved to be an important influencing factor. 


\section{MODELLING APPROACH}

When selecting the approach for modelling the landslide susceptibility one has to consider, that the general term "landslide" includes a broad variety of very different processes - ranging from slow deep-seated complex creeping movements to rapid shallow translational slides and slope debris flows (cf. [4]). Relevant influencing factors and process relations differ as much as the effects of these processes. Thus, different approaches for deep-seated and shallow landslides have to be chosen.

The indicative hazard map for deep-seated landslides was provided using a statistical approach. Currently, such methods allow the highest objectivity possible regarding landslide hazard analysis because influencing factors of slope instabilities and their interrelations may be evaluated using statistical models (cf. [3], [8]). The basic principle of the statistical modelling is the assumption that future landslides will occur with highest probability under similar environmental conditions as at the activation of past and present slope instabilities. The statistical correlation of a dependent target variable (mass movement incidence) with a set of independent explanatory variables, e.g. morphometric characteristics, geology, land cover etc. is analyzed. Logistic regression was used for the present study. With regard to the selection of the explanatory variables it is essential to use variables without interdependencies as far as possible. This requirement cannot always be realized entirely as most of the influencing parameters have more or less significant internal correlations. One of the main advantages of the applied multiple logistic regression is the possibility to use continuous, binary as well as categorical variables simultaneously. The method was tested intensely and proved to provide stable results [7].

For shallow landslides area-wide and representative landslide inventories only exist in exceptional cases (e.g. in the Styrian communities Gasen and Haslau after the precipitation event in August 2005). Neither is exact identification and mapping based on high resolution ALS-data normally possible. Hence, for shallow landslides a different approach was selected combining deterministic and statistical modelling methods. The Infinite Slope Model is widely used for conclusions about the stability of shallow translational slides [5], [6]. However, this model is not suitable for the generation of Indicative Hazard Maps solely as the level of information is not sufficient for large areas. Using available data sources with regard to geotechnical parameters like cohesion and friction angle, the deterministic approach therefore was applied for the derivation of a "hypothetic" landslide inventory. This inventory was then used as training dataset for the statistical modelling based on logistic regression. Forest parameters, forest road networks, tectonics, lithology, slope, curvature and runoff disposition were considered as explanatory variables for the statistical susceptibility modelling. The modelling was performed separately for each of the defined 16 geotechnical-lithological main units. Verification of the results was done by field checks, orthophoto interpretation and analysis of the high resolution DTM. Only potential release areas were modelled in this project phase; the modelling of propagation zones of shallow slides and slope debris flows is planned in a future phase.

\section{RESULTS}

The results of the presented work are Indicative Hazard Maps for the whole area of the Province of Styria in a 10m grid covering the following processes: 
- deep-seated landslides (Fig. 4A)

- shallow landslides (Fig. 4B)

- stone and rock falls

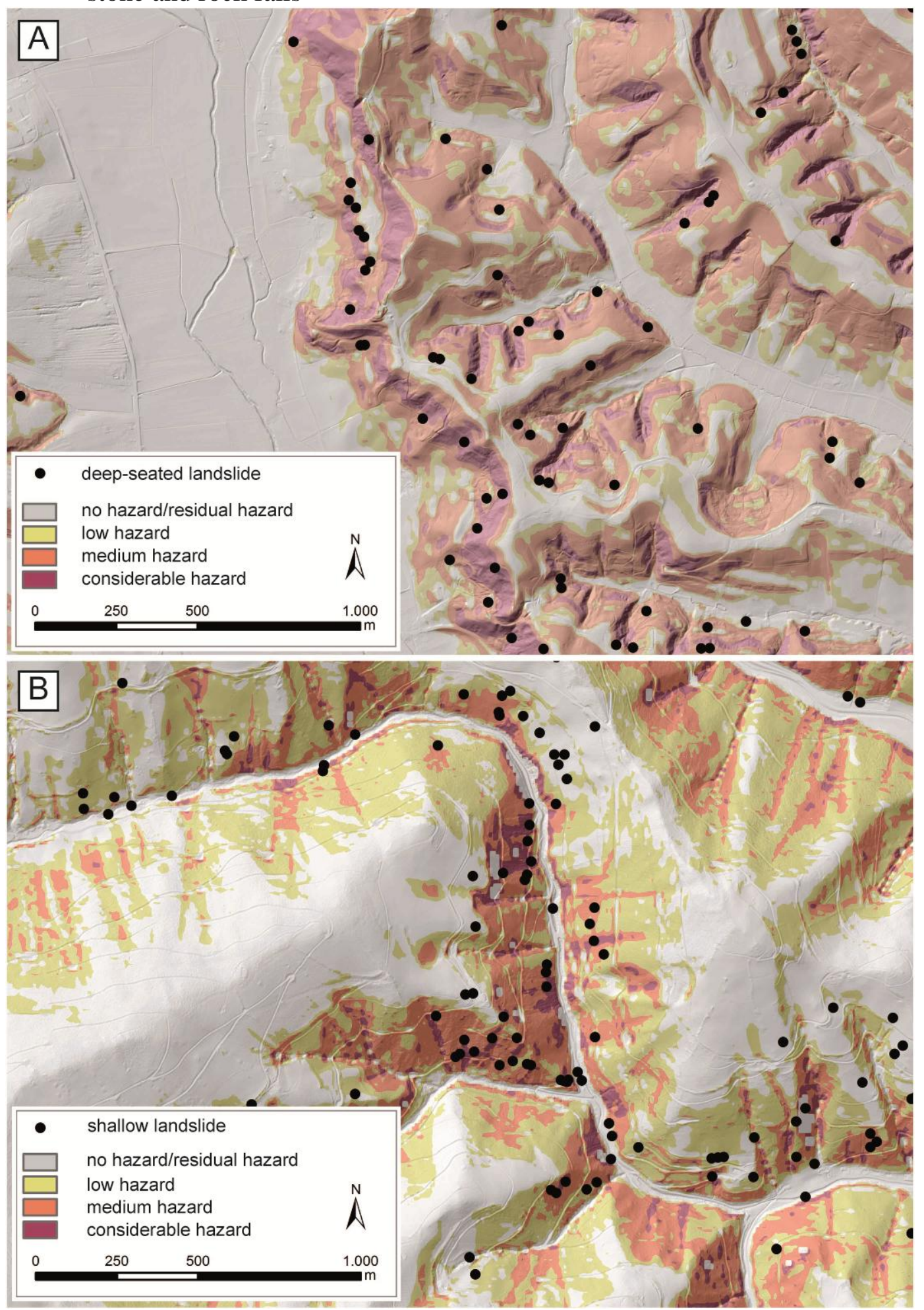

Figure 4: Details of the indicative hazard maps for deep seated landslides (A) in the District Southeastern Styria (A) and for shallow landslides in the District Weiz (B) 
Four hazard categories are shown: (1) no hazard or residual hazard, (2) low hazard, (3) medium hazard, and (4) considerable hazard, cf. Fig 4 A, B.

This legend follows the Swiss recommendations for spatial planning and natural hazards for hazard maps [2].

\section{CONCLUSIONS}

Indicative Hazard Maps may contribute substantially to identify areas which are potentially endangered by natural hazards. If applied properly, such maps are suited for minimizing or avoiding future risks and damages. Due to its methodological approach and applied modelling methods, Indicative Hazard Maps do not allow for conclusions down to the individual lot-level nor are they suitable to replace an expert's slope stability survey. Possible conclusions are restricted to the scale of 1:25.000. Their explanatory power cannot be increased by a stronger enlargement or zooming in. Special emphasis has to be given to the use of up to date and reliable data sources as well as to their reference to the process in focus. Reliable and reproducible modelling methods have to be selected and the modelling results have to be validated by state of the art methods.

\section{REFERENCES}

[1] Bell R., Petschko H., Proske H., Leopold P., Heiss G., Bauer C., Goetz J., Granica K. \& Glade T. Methodenentwicklung zur Gefährdungsmodellierung von Massenbewegungen in Niederösterreich - MoNOE, Unveröff. Endbericht. Wien, 2005.

[2] Bundesamt für Raumentwicklung, Bundesamt für Wasser und Geologie, Bundesamt für Umwelt, Wald und Landschaft (ed.). Empfehlung Raumplanung und Naturgefahren. Bern, 2005.

[3] Chung C.J. \& Fabbri A.G. Validation of spatial prediction models for landslide hazard mapping. Natural Hazards, 30, pp 451-472, 2003.

[4] Cruden D.M. \& Varnes D.J. Landslide types and processes. In: Turner A.K., Schuster R.L. (ed.), Landslides: investigation and mitigation. Special Report. National Academy Press, pp 36-75, 1996.

[5] Montgomery D.R. \& Dietrich W.E. A physically based model for the Topographic control on shallow landsliding. Water Resources Research, 30(4), pp 1153-1171, 1994.

[6] Pack R.T., Tarboton D.G. \& Goodwin C.N. The SINMAP Approach to Terrain Stability Mapping, 8th Congress of the International Association of Engineering Geology, Canada, 1998, pp. 1157-1165.

[7] Tilch N., Aust G., Bauer Ch., Fromm R., Granica K., Hagen K., Haiden Th., Herzberger E., Kleb U., Klebinder K., Kornberger B., Perzl F., Pistotnik G., Proske H. \& Schwarz L. AdaptSlide - Modelling of Landslide Susceptibility and affected Areas - Process-specific Validation of Databases, Methods and Results for the Communities of Gasen and Haslau. Unveröff. Endbericht, GBA Wien, 2011. 
[8] Van Westen C.J., van Asch Th.W.J. \& Soeters R. Landslide hazard and risk zonation: why is it still so difficult? Bulletin of Engineering Geology and the Environment IAEG, 65 (2006) 2, pp 167-184, 2006. 